\title{
DESIGN IMPROVISATION OF ELECTRO- MECHANICAL ACTUATORS FOR OPERATION AT SUB ZERO TEMPERATURES
}

\author{
Sangeetha Singhal ${ }^{1}$, VijayaKumar ${ }^{2}$, Safeer $_{\text {Ahmed }}^{3}$, H S Nagaraj ${ }^{4}$ \\ ${ }^{1}$ Scientist, Aeronautical Development Establishment, DRDO, Bangalore \\ sangeetha@ade.drdo.in \\ 2,3,4 Technical officer, Aeronautical Development Establishment, DRDO, Bangalore \\ nagahs08@gmail.com, safeeryunusegmail.com
}

\begin{abstract}
Control surface actuators are the key systems in any flight vehicle for enabling a strict control on the flight parameters. The electromechanical actuator developed for an Unmanned aerial vehicle (UAV) is subjected to sub-zero temperatures due to the altitude of operation. This paper discusses on how an actuator developed is studied experimentally and improvised in design to ensure performance at $-40^{\circ} \mathrm{C}$. The experimental observations are reasoned and supported by theoretical studies and remedial measures incorporated to improve the actuator performance.
\end{abstract}

\section{KEYWORDS}

Electromechanical actuators, Unmanned aerial vehicles, failure analysis, lubricant, sub-zero temperature,

\section{INTRODUCTION}

Control surface actuators are the crucial systems for any flight vehicle. They counter the hinge moments on the control surfaces due to aero dynamic forces so as to manoeuvre the vehicle in the required flight path. In particular to unmanned aerial vehicles (UAV), these actuators need to be high precision, low weight, low cost, small in size and least complicated logistically. UAV applications being the lower range of power and dynamic response may well be satisfied with electro mechanical actuators. The low weight and packaging flexibility of these provide an added advantage. No extra logistic is involved for electromechanical actuators due to the availability of the electrical power from the engine.

A linear actuator is designed and developed to actuate control surfaces of an UAV. The actuator consists of a BLDC motor as prime mover, LVDT as position feedback and a roller screw for load transmission, housings for motor and bearing. The realised system with a load capacity of $670 \mathrm{~N} / 1350 \mathrm{~N}$ (continuous/peak) and accuracy of $\pm 0.25 \mathrm{~mm}$ is as shown in Figure 1 .

Roller screws offer better load ratings and shock resistance due to the large number of contact points provided by roller screw design compared to ball screws and acme threads. Due to the constrained space and high stiffness demand, roller screw with a lead of $1 \mathrm{~mm}$ and a class of accuracy of G5 has been selected for the design [4] [5]. The Roller Screw-Nut assembly is directly coupled to the rotor shaft, thereby converting the rotary motion of the motor into the linear motion of the roller nut. The roller nut is preloaded to eliminate axial play and increase rigidity. The standard roller screw is modified to satisfy the mounting requirements, where in a 
collar is introduced for load transmission as shown in Figure 2. An angular contact-duplex bearing is introduced at this interface to take care of the axial and radial loads arising due to the roller screw motion. The mounting arrangement of the roller screw with the associated bearing is as shown in Figure 3a. The collar ensures that the associated duplex bearings get preloaded to the required value.

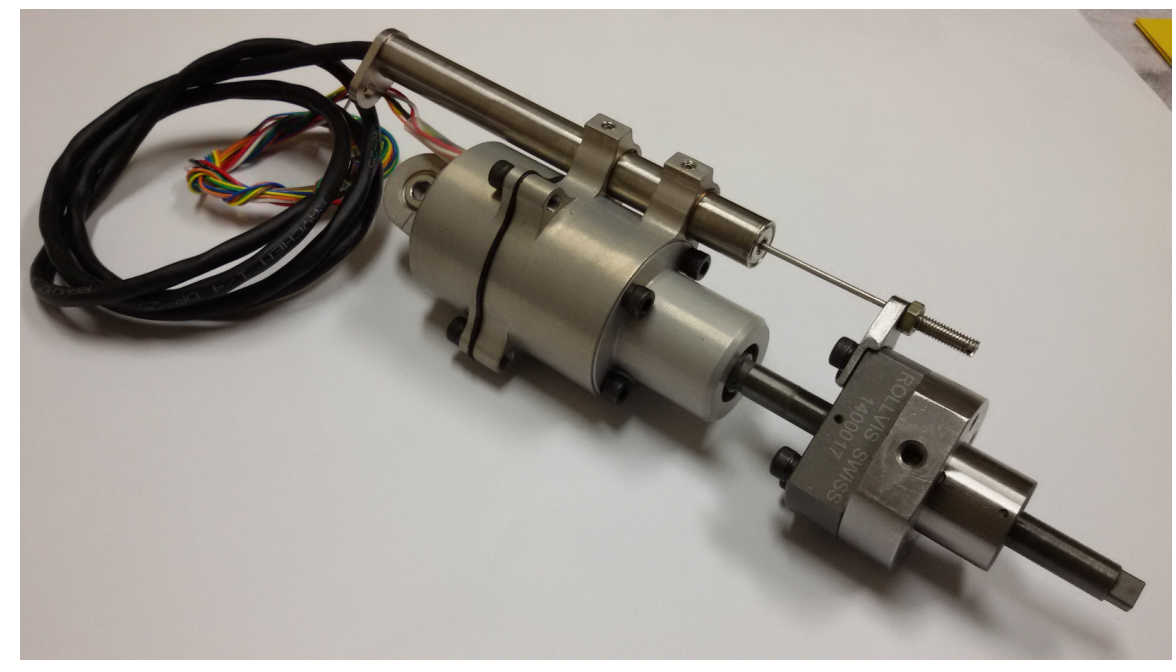

Figure1: The actuator developed for a UAV programme

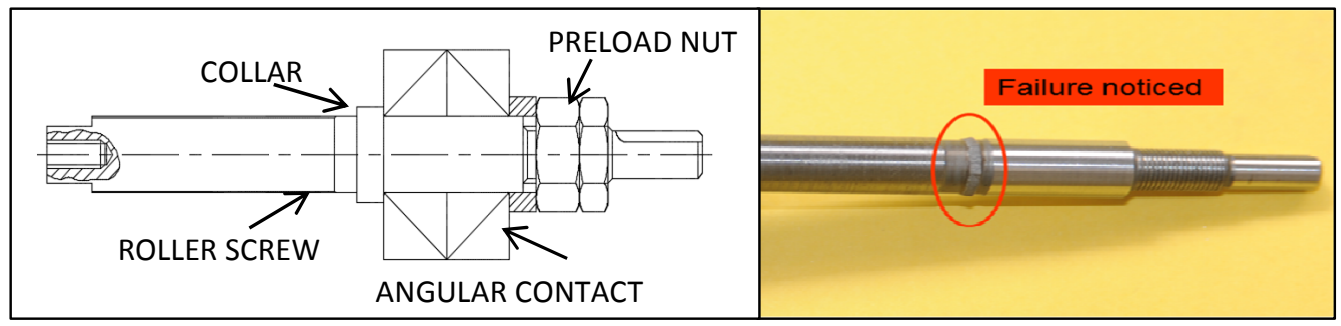

Figure 2: a) Bearing preloaded against collar b) Failure at roller screw after operation at $-40^{\circ} \mathrm{C}$

The environmental specifications for the actuator design are revised to cater to the expansion of flight envelope of the UAV. As per the revised test schedule, the actuator is tested at $-40^{\circ} \mathrm{C}$ in place of $-20^{\circ} \mathrm{C}$. When the actuator is tested at $-40^{\circ} \mathrm{C}$, the collar provided on the roller screw for load transmission failed under no load condition (preload $9649 \mathrm{~N}$ existing) as shown in Figure $3 \mathrm{~b}$. Theoretical and experimental studies are conducted to analyse the failure cause and remedial measures are implemented for ensuring the actuator performance at $-40^{\circ} \mathrm{C}$.

\section{EXPERIMENTAL AND THEORETICAL ANALYSIS}

The failure of the roller screw is studied and the probable reasons were discussed on for initiation of the implementation of remedial measures. Initially, following reasons were identified for the probable reasons for failure:

1. Probable degradation of the mechanical properties with temperature and hence the inability of the collar to sustain the preload.

2. Failure initiated due to stress concentration at the sharp corner of the collar or due to the case hardening depth at the collar. (The screw is completely case hardened to the depth of 
$0.8 \mathrm{~mm}$ to $1.2 \mathrm{~mm}$ up to $56-60 \mathrm{HRC}$. This implies that the collar is more or less lying in the case hardened depth which tends to be brittle.)

3. Higher preload values

Deterioration of mechanical properties of the material is ruled out since the DBT temperature of the steel used for the roller screw is not in the test temperature range. Rest of the observations are addressed with the roller screw modified with increased collar thickness (1mm to $3 \mathrm{~mm}$ )for increased shear area, fillet radius at the intersection between collar and shaft to avoid stress concentration and local masking of the collar while case hardening to ensure sufficient ductile core in the collar to resist loads at $-40^{\circ} \mathrm{C}$. Further experimental studies are conducted to study the effect of preloads.

\subsection{Experimental validation for preload}

The actuator with original roller screw is assembled with lower preload value. The actuator is soaked for an hour at $-40^{\circ} \mathrm{C}$ and tested. The failure is not observed and the tightening torques is found to be not different from the assembled condition. It is inferred that the roller screw material is capable of operating at $-40^{\circ} \mathrm{C}$ with lesser preload.

The test is repeated with different preload values. After one of the experiment, when the actuator is dismantled and checked, the tightening torque of the preload nut is found to have increased by 10 times of the initial value. (i.e from $30 \mathrm{Ncm}$ to around $300 \mathrm{~N}-\mathrm{cm}$ ).

From the literature studies [1], it is understood that the preload increased at lower temperatures while got relieved at higher temperatures. The roller screw is of steel while the housing of the bearing is of aluminium alloy. The axial load caused by a difference in the coefficients of thermal expansion of the preloaded joint and the housing caused a positive thermal load increasing the preload at negative temperature, and the negative thermal load that decreased the preload at higher temperature.

Theoretical estimations are carried out and compared with the experimental values. The attributes of the housing and the screw are Length $(\mathrm{L})=26 \mathrm{~mm}$, Area of the screw $(\mathrm{A})=20.1$ $\mathrm{mm}^{2}$. For a temperature difference $\Delta \mathrm{T}$ of $-60^{\circ} \mathrm{C}$, differential contraction $\delta$ is estimated as $0.02 \mathrm{~mm}$. This results in a positive thermal load of $3317.71 \mathrm{~N}$ at $-40^{\circ} \mathrm{C}$. The additional preload at the nut corresponds to $370 \mathrm{Ncm}$ which matches with the observation of experiment. Hence the roller screw was subjected to a total force of $12895 \mathrm{~N}(9649 \mathrm{~N}$ (assembly preload) $+3317.71 \mathrm{~N}$ (thermal)) at $-40^{\circ} \mathrm{C}$ which resulted in a factor of safety of 0.76 for $1 \mathrm{~mm}$ thick collar, thus resulting in failure.

The failure is attributed solely to the thermally induced variations in the preload. Based on this study, tightening torque got quantized. The preload value is ensured sufficient to take care of the preload loss and uncertainty of the tightening process. Uncertainty in torque measurement is assumed to be $30 \%$ of the tightening torque and preload loss is assumed to be $5 \%$ of the maximum preload [1]. The tightening torque is fixed at $0.75 \mathrm{Nm}$ which results in a maximum preload of $856 \mathrm{~N}$ and a minimum preload of $420 \mathrm{~N}$ which suffices the bearing stiffness characteristic. The roller screw is now subjected to a total force of $2206 \mathrm{~N}$ (1350 N (peak load) + $856 \mathrm{~N}$ (thermal)) at $-40^{\circ} \mathrm{C}$. This results in a factor of safety of 4.47 for $1 \mathrm{~mm}$ thick collar and 13.42 for $3 \mathrm{~mm}$ thick even at peak load. The housing material shall also be changed to stainless steel to eliminate the thermal load due to differential thermal expansion. 


\subsection{Experimental validation for loaded operation}

The new configuration of actuator (with bearing housing converted to stainless steel) is soaked and tested at no load and found to withstand $-40^{\circ} \mathrm{C}$ temperature. The collar is intact in spite of tightening preload nut to $10.6 \mathrm{Nm}$ which gives immense confidence in failure free operation of the system at peak load even at $-40^{\circ} \mathrm{C}$. The actuator is loaded to full operating load of $670 \mathrm{~N}$ as shown in Figure 3 and tested again. At every temperature the actuator is soaked in OFF condition and switched $\mathrm{ON}$ and commanded to operate.

The roller screw collar is found intact. But the peak current drawn during the operation at $-40^{\circ} \mathrm{C}$ is observed to be high and the actuator is found not to respond to the commands. The current drawn during the experiment are as tabulated in Table 1.

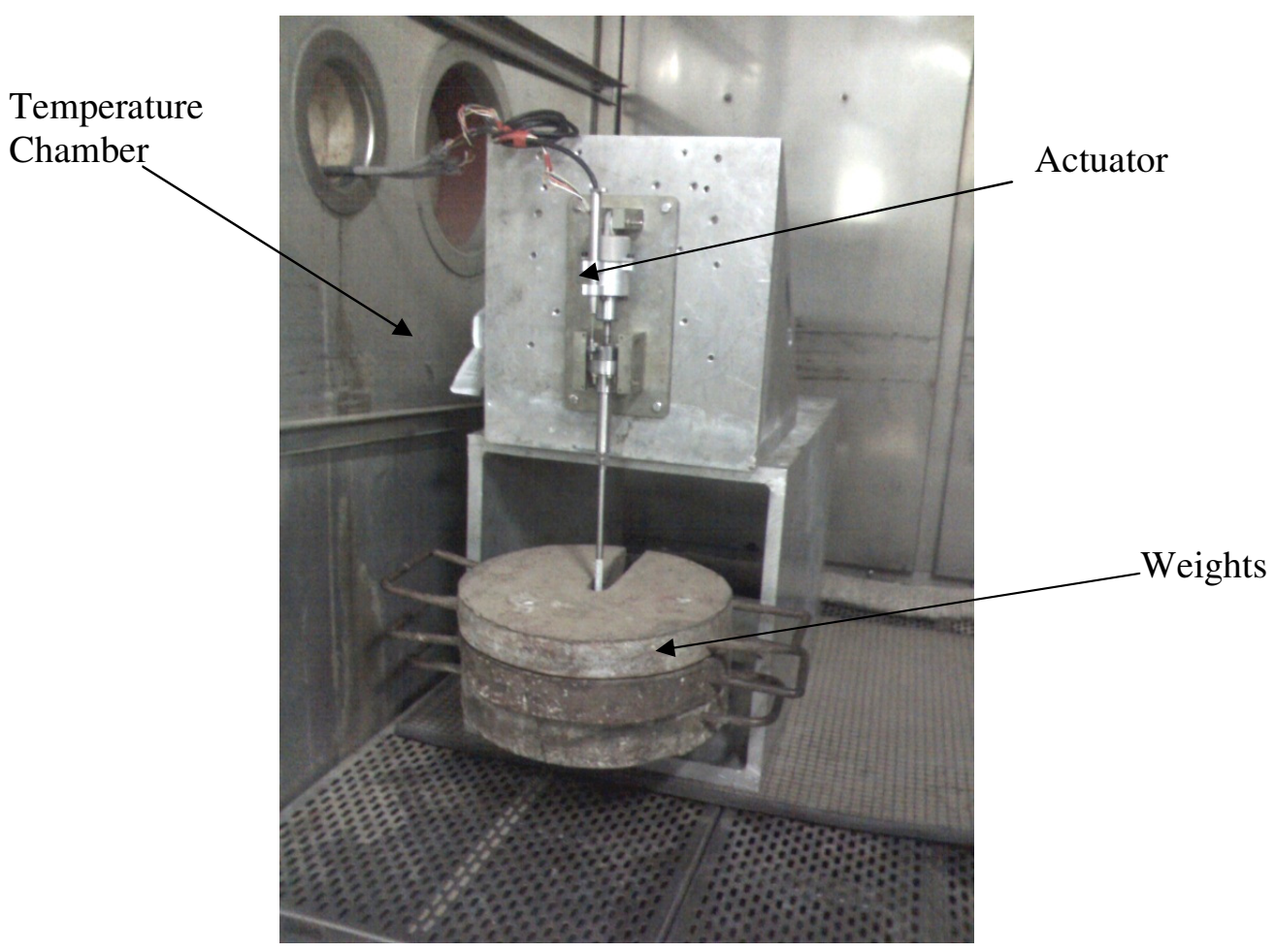

Figure 3: The test setup for loaded test of roller screw actuator in Temperature chamber

\begin{tabular}{|l|l|l|l|}
\hline Temperature $\left({ }^{\mathbf{}} \mathbf{C}\right)$ & Amplitude (V) & Frequency(Hz) & Current (A) \\
\hline Ambient & 2 peak to peak & 0.1 & 0.4 \\
\hline-20 & 2 peak to peak & 0.1 & 1.8 \\
\hline-30 & 2 peak to peak & 0.1 & 2.8 \\
\hline-35 & 2 peak to peak & 0.1 & 4.8 \\
\hline-40 & 2 peak to peak & 0.1 & -- \\
\hline
\end{tabular}

Table 1: Current drawn by actuator during the experimental study

The inability of the actuator to respond at $-40^{\circ} \mathrm{C}$ is probably attributed to thermal stresses in the bearings due to differential thermal expansion of the motor housing (HE-15 WP, coefficient of thermal expansion $\left.=23.6 \times 10-6 \mathrm{~m} / \mathrm{m} /{ }^{\circ} \mathrm{C}\right)$ and the bearing material $(\mathrm{X} 65 \mathrm{Cr} 13$, coefficient of thermal expansion $=10.5 \times 10-6 \mathrm{~m} / \mathrm{m} /{ }^{\circ} \mathrm{C}$ ). 
The pressure $\mathrm{p}$, acting on the outer race of the bearing, can be calculated from the following relation,

$$
\frac{p D^{2}}{2} \cdot\left(\frac{1}{t_{a} E_{a}}+\frac{1}{t_{s} E_{s}}\right)=\left(\alpha_{\mathrm{a}}-\alpha_{\mathrm{s}}\right) \cdot \Delta \mathrm{T} . \mathrm{D}
$$

The pressure results in the reduction of radial clearance in the bearing $R V_{t}$ given by,

$$
R V_{t}=\frac{p D^{2}}{2 t_{s} E_{s}}
$$

Where,

$\alpha_{\mathrm{a}, \mathrm{s}} \quad=$ co-efficient of thermal expansion for Al. alloy(a) and steel(s)

$\mathrm{D}=$ effective Bearing diameter

$\mathrm{t}_{\mathrm{a}, \mathrm{s}} \quad=$ thickness of the aluminum housing(a) and steel(s)

$\mathrm{E}_{\mathrm{a}, \mathrm{s}} \quad=$ Modulus of elasticity Al. alloy(a) and steel(s)

The radial clearances for the bearings is estimated and found to contract through 6 microns to 17 microns. The bearings currently used are specified with a radial clearance of $\mathrm{C} 2$ which has radial clearance insufficient to accommodate the reduction in clearance resulting due to differential thermal expansion. This results in increase in friction while operating thus resulting in drawing higher currents. To study the effect of this the actuator is assembled with stainless steel housing and the tests repeated in loaded condition. The results are as tabulated in Table2.

\begin{tabular}{|l|l|l|l|}
\hline Temperature $\left({ }^{\circ} \mathbf{C}\right)$ & Amplitude $(\mathbf{V})$ & Frequency $(\mathbf{H z})$ & Current (A) \\
\hline Ambient & 2 peak to peak & 0.1 & 0.8 \\
\hline-20 & 2 peak to peak & 0.1 & 1.6 \\
\hline-30 & 2 peak to peak & 0.1 & 2.8 \\
\hline-35 & 2 peak to peak & 0.1 & 4.4 \\
\hline-40 & 2 peak to peak & 0.1 & 4.5 \\
\hline
\end{tabular}

Table 2: Current drawn by actuator during the experimental study

The performance of the system improved marginally and is not enough to ensure the performance throughout the temperature range. The actuator didn't respond again at $-40^{\circ} \mathrm{C}$ initially and started responding after 15 minutes. It is also found that the roller screw and nut assembly had jammed and the lock nut of the angular contact bearing is loosened and preload nut torque had come down to $25 \mathrm{~N}-\mathrm{cm}$. It is inferred that the friction has increased drastically at $-40^{\circ} \mathrm{C}$.

These observations lead in to the study of the lubricant used initially for the roller screw assembly. The roller screw is greased by OEM with ISOFLEX TOPAS NCA 52 which is cleared for $-55^{\circ} \mathrm{C}$ to $+85^{\circ} \mathrm{C}$. The characteristic of this lubricant is an exponential increase in viscosity at sub-zero temperatures. Alternate greases are searched for; with flatter viscosity versus sub-zero temperatures characteristic. One such grease is AeroShellgrease-17; MIL-G-21164 which is approved from $-73^{\circ} \mathrm{C}$ to $149^{\circ} \mathrm{C}$ and particularly suitable for lubricating heavily loaded sliding steel surfaces [2]. The viscosity of ISOFLEX TOPAS at $-40^{\circ} \mathrm{C}$ is $11312 \mathrm{cST}$ while that of AeroShellgrease-17 is $1150 \mathrm{cST}$. The roller screw assembly got re-greased with AeroShellgrease17 by OEM and got assembled in the actuator. 
Since the improvement in the performance is minimal with the introduction of steel housing, and thermal conductivity characteristic of steel is inferior to steel, the actuator housing is retained as aluminium alloy housing. The actuator is tested with re-greased roller screw assembly and the values are tabulated as in Table 3.

\begin{tabular}{|l|l|l|l|}
\hline Temperature $\left({ }^{\circ} \mathbf{C}\right)$ & Amplitude $(\mathbf{V})$ & Frequency(Hz) & Current (A) \\
\hline Ambient & 2 peak to peak & 0.1 & 2 \\
\hline-20 & 2 peak to peak & 0.1 & 2 \\
\hline-30 & 2 peak to peak & 0.1 & 2.2 \\
\hline-35 & 2 peak to peak & 0.1 & 2.4 \\
\hline-40 & 2 peak to peak & 0.1 & 2.8 \\
\hline
\end{tabular}

Table 3: Current drawn by actuator during the experimental study

The actuator characteristic improved considerably to meet the specification without performance degradation at sub-zero temperature.

\section{Conclusions}

The performance of an electromechanical actuator is studied at sub-zero temperature. The quantization of the preload torque and having bearing housing made of steel ensured failure free operation at $-40^{\circ} \mathrm{C}$. The friction in the actuator assembly considerably increased at $-40^{\circ} \mathrm{C}$ leading to jamming of the assembly. Experiments are conducted with the housing changed to steel so as to relieve the thermal load on bearings. But this offered only marginal improvement in the performance the actuator assembly. Thence the actuator is assembled with re-greased roller screw assembly (AeroShellgrease-17, MIL-G-21164 in place of ISOFLEX TOPAS NCA 52) and tested. This offered all the more consistent friction over the temperature range and ensured the actuator performance at sub-zero temperature.

\section{ACKNOWLEDGEMENTS}

Our work is a culmination of good will; guidance and encouragement of our divisional head Mr.N RadhaKrishna . We would like to thank Mr. Jerome Marshal without whom a project of this magnitude would not have been completed to this quality. We would like to express our heartfelt thanks to Sri P. Sri Kumar, Sc'H', OS, Director, ADE for kindly permitting us present this work.

\section{REFERENCES}

[1] Criteria for preloaded bolts, NASA (Reference: NSTS 08307 Revision A, July6, 1998)

[2] Aeroshell book, Edition 18, 2003

[3] Mechanical Engineering Design, Joseph E Shigley and Charles R Mischke, Sixth edition

[4] Satish, Sangeetha, Pollov,(2008) "Actuation mechanism of control surface of an unmanned air vehicle", ARMS conference 2008, ARDE, Pune

[5] ADE/MED/16/07-08, Mechanical Engineering Design of Linear Actuators(Internal report of ADE)

\section{Author:}

\section{Sangeetha Singhal}

BTech in Production Engg and Mgt(NIT Calicut 2003) and MTech in Machine Design (IIT-Madras 2009). Working as a scientist at Aeronautical Devt Estt, DRDO since Aug 2003.

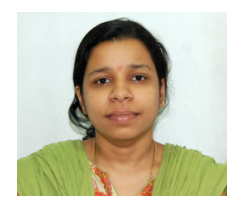

